J. Lake Sci. (湖泊科学) , 2015, 27(5): 865-872

DOI $10.18307 / 2015.0512$

(C) 2015 by Journal of Lake Sciences

\title{
太湖贡湖湾和梅梁湾微囊藻群落的时空分布及其驱动因子"
}

\author{
孙千千 ${ }^{1}$, 朱 伟 ${ }^{1,2}$, 李 明 $^{3}$ \\ (1: 河海大学环境学院, 南京 210098) \\ ( 2 : 水资源高效利用与工程安全国家工程研究中心, 南京 210098$)$ \\ $(3:$ 西北农林科技大学资源环境学院,杨凌 712100)
}

摘 要: 于 2010 年 7 月至 2011 年 6 月期间, 对太湖贡湖湾及梅梁湾微囊藻的种类组成及其群落的时空分布差异进行调 查, 并探讨影响微囊藻群落时空分布的环境因子. 结果表明, 7-11 月太湖贡湖湾和梅梁湾都表现为鱼害微囊藻 (Microcystis ichthyoblabe)、惠氏微囊藻 (M. wesenbergii) 及铜绿微囊藻 (M. aeruginosa) 顺次成为优势种的演替过程, 其余时间段内以 鱼害微囊藻及其它微囊藻为主. 通过 CCA 分析环境因子与微囊藻属内各种类之间的关系, 发现温度是驱动其季节演替的 主要因素. 两个湖湾之间及同一个湖湾内中心与岸边区域的微囊藻种属分布差异不明显. 但是受到风的作用,两个湖湾 中下风向位置的微囊藻细胞丰度较高. 惠氏微囊藻和铜绿微囊藻更易受到风的影响而向下风向位置迁移,这是因为惠氏 微囊藻和铜绿微囊藻群体粒径相对较大, 易于漂浮在表层而通过表层迁移聚集于下风向处. 可见风引起的表层迁移是影 响微囊藻群落空间分布的重要因素.

关键词: 太湖;微囊藻;季节演替;时空分布;风;贡湖湾;梅梁湾

\section{Spatial and temporal variations of Microcystis colonies and their influencing factors in Gonghu Bay and Meiliang Bay of Lake Taihu}

SUN Qianqian ${ }^{1}$, ZHU Wei ${ }^{1,2}$ \& LI Ming ${ }^{3}$

(1: College of Environment, Hohai University, Nanjing 210098, P. R. China)

(2: National Engineering Research Center of Water Resources Efficient Utilization and Engineering Safety, Nanjing 210098, P. R. China)

(3: College of Resources and Environment, Northwest Agriculture and Forest University, Yangling 712100, P. R. China)

Abstract: Spatial and temporal variations of Microcystis species composition in Gonghu Bay and Meiliang Bay in Lake Taihu were observed from July 2010 to June 2011. The relationship between seasonal succession of Microcystis colonies and environmental factors was also analyzed. The results showed that $M$. ichthyoblabe, M. wesenbergii and M. aeruginosa were dominated successively during July to September, and only $M$. ichthyoblabe and other Microcystis can be found in winter and early spring. CCA analysis revealed that temperature was the main factor driving this seasonal succession. No difference was found in spatial distribution of $\mathrm{Mi}$ crocystis between the two bays, nor was that between the central and coastal areas in the same bay. However, the cell abundance of Microcystis in the downwind area was greater than that in the upwind area, especially that of $M$. wesenbergii and M. aeruginosa. The size of $M$. wesenbergii and $M$. aeruginosa colonies was relatively larger, which made them float to the surface and migrate by the wind much easier. Thus, it was concluded that surface migration caused by wind was an important factor in the spatial distribution of Microcystis colonies.

Keywords: Lake Taihu; Microcystis; seasonal succession; spatial and temporal distribution; wind; Gonghu Bay; Meiliang Bay

蓝藻水华的频繁发生, 造成了一系列生态和环境问题 ${ }^{[1-2]}$. 其中微囊藻属是水华蓝藻中分布最广、危害 最严重的属 ${ }^{[3]}$. 一些湖泊调查结果显示, 微囊藻群落存在明显的季节演替规律. Park 等 ${ }^{[4]}$ 对日本诹访湖微囊

* 江苏省科技基础设施建设计划项目 (BM2013013) 和国家自然科学基金项目 (51278165) 联合资助. 2014-12-29 收稿;2015-04-22 收修改稿. 孙千千(1990 ), 女,硕士研究生;E-mail : zhuweiteam. hhu@ gmail. com. 
藻种类组成进行调查, 发现在 6-8 月间水华微囊藻 (Microcystis flos-aquae) 和惠氏微囊藻 (M. wesenbergii) 不 断增多而占优势, 9 月之后铜绿微囊藻 $\left(M\right.$. aeruginosa) 不断增多而占优势. 在日本琵琶湖 ${ }^{[5]}$ 、Hirosawa-no-ike pond $^{[6]}$ 和我国的巢湖 ${ }^{[7]}$ 都发现了类似的规律.

太湖是我国第 3 大淡水湖泊,近年来, 夏季蓝藻水华频繁发生, 其中铜绿微囊藻、水华微囊藻和惠氏微 囊藻为主要优势种, 占蓝藻总丰度的 $90 \%$ 以上 ${ }^{[8]}$. 谭啸等 ${ }^{[9]}$ 比较分析了太湖春、夏、秋、冬季微囊藻群落的组 成, 并未发现明显的季节变化规律. 而 $\mathrm{Li}^{\text {等 }}{ }^{[10]}$ 发现太湖中微囊藻群落存在显著的季节演替现象, 铜绿微囊 藻和惠氏微囊藻在夏、秋季占优势, 而较小的鱼害微囊藻 ( M. ichthyoblabe) 在春季与冬季大量存在, 但并没 有对不同微囊藻的空间差异进行探讨. Otten 等 ${ }^{[11]}$ 在 2009 年 6-7 月及 2010 年 7 月对太湖的调查发现,太 湖中微囊藻群落存在明显的空间差异. 以上学者逐步提出了太湖微囊藻群落的演替规律及空间分布差异, 但季节演替结果存在差异, 且不同区域微囊藻群落的空间差异仍需要进一步明确. 此外, 有学者对微囊藻种 类间季节性演替的机理进行了探讨. Imai 等 ${ }^{[12]}$ 通过野外调查发现铜绿微囊藻占优势时水温在 $24.7 \sim$ $33.9^{\circ} \mathrm{C}$ 之间, 而惠氏微囊藻占优势时水温为 $19.6 \sim 28.6^{\circ} \mathrm{C}$, 且通过室内培养实验发现高温条件下铜绿微囊 藻的生长速率明显高于惠氏微囊藻, 因此提出水温可能是影响微囊藻群落演替的重要因素. Amemiya 等 ${ }^{[13]}$ 对采自日本诹访湖的微囊藻进行室内培养, 发现溶解性无机氮 (DIN) 浓度与铜绿微囊藻生长速率呈正相关, 与绿色微囊藻 (M. viridis) 生长速率呈负相关, 而温度对几种微囊藻的生长并没有明显的影响. 此外, 有研究 者通过室内培养实验发现铜绿微囊藻、惠氏微囊藻对于 $\mathrm{P}$ 和 $\mathrm{Fe}$ 等的最适浓度存在差别 ${ }^{[14-15]}$. 尽管对微囊藻 种类间季节演替的机理已开展研究, 但所得结论不一致 ${ }^{[12,21]}$, 且缺少野外环境中多种微囊藻同时存在时各 种环境因子与微囊藻种类间的相关性分析.

本研究于 2010 年 7 月至 2011 年 6 月期间对太湖梅梁湾和贡湖湾进行为期一年的调查, 观察微囊藻群 落构成的季节变化及其在空间上的差异, 并探讨影响微囊藻群落时空分布的因素.

\section{1 材料和方法}

\section{1 采样点布置及样品采集}

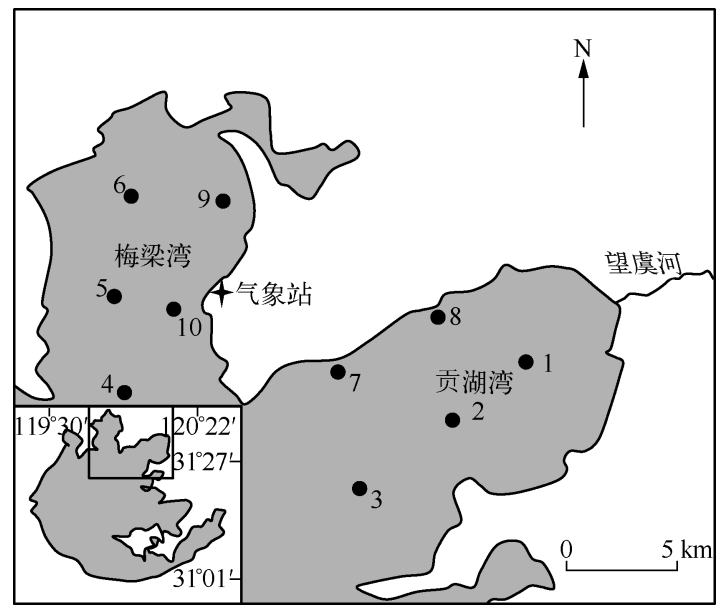

图 1 太湖梅梁湾与贡湖湾各采样点分布

Fig. 1 Sampling sites in Meiliang Bay and Gonghu Bay of Lake Taihu

在太湖北部梅梁湾及贡湖湾各设置 5 个采样 点( 图 1),于 2010 年 7 月初到 2011 年 6 月初每月 采样 1 次. 用有机玻璃采水器采集水面以下 $30 \mathrm{~cm}$ 处水样并保存于 $500 \mathrm{ml}$ 聚乙烯瓶中, 冷藏带回实 验室测定总溶解态氮 ( TDN) 、总溶解态磷 ( TDP) 浓度. 另取 $10 \mathrm{~L}$ 水样通过 $64 \mu \mathrm{m}$ 浮游植物网进行 藻样富集, 加人福尔马林固定后带回实验室进行 微囊藻种类及丰度分析. 现场用水温计 (Mettler $\mathrm{SG7})$ 及 $\mathrm{pH}$ 仪 ( $\mathrm{pH}$ Testr30) 测量水温及 $\mathrm{pH}$ 值. 并 通过 $10^{\#}$ 样点附近的气象站记录风速与风向.

\section{2 分析方法}

1.2 .1 水质指标的测定 根据《湖泊富营养化调查 规范》 ${ }^{[16]}$ 对水质指标进行监测. 将水样通过 $0.45 \mu \mathrm{m}$ 微孔滤膜过滤后, 分别测定水中 TDN 和 TDP 浓度.

1.2 .2 藻类组成和细胞丰度分析 将采集的藻样 摇匀后均匀分为两份. 一份用显微镜拍照 (奥林巴

斯 CX31 联同尼康 C-5050 数码相机), 然后用 UTHSCSA Image Tool v3.00 软件 (美国德克萨斯大学) 量取照片中所有微囊藻群体粒径, 每个样品至少量取 200 个群体, 用球型体积计算公式计算各微囊藻群体的体积, 并以此分析代表各种微囊藻的生物量比例. 藻 类鉴定依据虞功亮等 ${ }^{[17]}$ 的方法, 本研究将微囊藻分为鱼害微囊藻、惠氏微囊藻、铜绿微囊藻以及其它微囊 
藻. 其中水华微囊藻因与鱼害微囊藻形态相近较难区分, 本研究一并归为鱼害微囊藻 ${ }^{[18]}$.

将另外一份藻样摇匀, 取 $3 \mathrm{ml}$ 于离心管中, 在 $100^{\circ} \mathrm{C}$ 水浴振荡锅中以 120 转 $/ \mathrm{min}$ 振荡 $5 \mathrm{~min}$, 使藻细胞 分散开 ${ }^{[19]}$. 用血球计数板在显微镜 (Olympus CX31) 下对藻细胞数进行计数, 计数 3 次, 当 3 次误差小于 $10 \%$ 时以平均值表示细胞丰度, 否则再进行计数, 直到有 3 次的误差小于 $10 \%$. 各种微囊藻的细胞丰度通过 不同微囊藻所占比例与微囊藻总细胞丰度的乘积求得.

1.2.3 数据分析 各环境因子与各微囊藻细胞丰度间的关系通过 CANOCO 4.5 (SCIENTIA Software) 软件进行 典范对应分析 (CCA). 为探讨风对藻群体空间分布的影响, 将两个湖湾各点的不同微囊藻细胞丰度沿着风向 进行绘制, 并用 SPSS 10.0 软件对上风向和下风向各样点微囊藻细胞丰度分布之间的关系做单项方差分析.

\section{2 结果}

\section{1 调查期间气象与环境因子}

表 1 为太湖贡湖湾、梅梁湾不同月份主要气象因子及 $\mathrm{pH}$ 的变化情况. 其中水温及 $\mathrm{pH}$ 为各采样点的平 均值, 风速和风向为采样时段内气象站处的平均风速和风向, 风向以正北方向为 $0^{\circ}$, 顺时针表示. $7-9$ 月份 水温在 $30^{\circ} \mathrm{C}$ 左右, 之后逐渐降低,一直到 3 月份缓慢上升, 6 月平均水温为 $25.0^{\circ} \mathrm{C}$. 各采样时段内的 $\mathrm{pH}$ 值相 近,均在 8.0 左右. 平均风速为 $1.5 \sim 4.0 \mathrm{~m} / \mathrm{s}$. 风向主要表现为季风变化,7、8 月份以东南风为主, $9 、 10$ 月大 部分时间都受东北风的影响, 11 月至次年 3 月则主要为西北风,之后又逐渐受东南风影响.

将 2 个湖湾以湖心及沿岸进行区域划分, 分为 4 个区域, 即贡湖湾湖心及沿岸、梅梁湾湖心及沿岸. 对各 区域进行统计分析,得到贡湖湾及梅梁湾湖心及沿岸区域水体 TDN 和 TDP 的平均浓度(图 2). 结果表明,梅 梁湾水体中 TDP 平均浓度均比贡湖湾高, 而不同湖湾水体的 TDN 平均浓度没有明显的规律, 同一湖湾不同 区域间的 TDN、TDP 平均浓度规律性也不明显.

表 1 太湖贡湖湾、梅梁湾不同月份主要气象因子及 $\mathrm{pH}$ 的变化

Tab. 1 Meteorological factors and $\mathrm{pH}$ in different months in Gonghu Bay and Meiliang Bay of Lake Taihu

\begin{tabular}{ccccc}
\hline 月份 & 水温 $/{ }^{\circ} \mathrm{C}$ & $\mathrm{pH}$ 值 & 风速 $/(\mathrm{m} / \mathrm{s})$ & 风向 $/^{\circ}$ \\
\hline 月 & $30.2 \pm 0.77$ & $8.1 \pm 0.28$ & $3.5 \pm 0.90$ & 125 \\
8 月 & $33.1 \pm 0.22$ & $8.7 \pm 0.20$ & $3.3 \pm 0.97$ & 167 \\
9 月 & $29.3 \pm 0.51$ & $8.3 \pm 0.32$ & $2.9 \pm 0.87$ & 55 \\
10 月 & $24.6 \pm 0.83$ & $8.8 \pm 0.30$ & $2.9 \pm 1.18$ & 63 \\
11 月 & $15.0 \pm 0.65$ & $7.9 \pm 0.11$ & $2.3 \pm 0.79$ & 332 \\
12 月 & $6.2 \pm 0.27$ & $8.1 \pm 0.09$ & $4.0 \pm 2.08$ & 346 \\
1 月 & $4.1 \pm 0.12$ & $8.3 \pm 0.15$ & $2.2 \pm 1.21$ & 297 \\
月 & $4.3 \pm 0.30$ & $8.0 \pm 0.22$ & $1.5 \pm 1.18$ & 306 \\
月 & $10.0 \pm 0.27$ & $7.9 \pm 0.21$ & $2.6 \pm 1.64$ & 97 \\
月月 & $17.5 \pm 0.41$ & $7.9 \pm 0.27$ & $2.0 \pm 1.28$ & 120 \\
月月 & $22.7 \pm 0.58$ & $8.5 \pm 0.33$ & $3.0 \pm 1.26$ & 175 \\
6月 & $25.0 \pm 0.53$ & $8.1 \pm 0.25$ & $1.7 \pm 0.90$ & \\
\hline
\end{tabular}
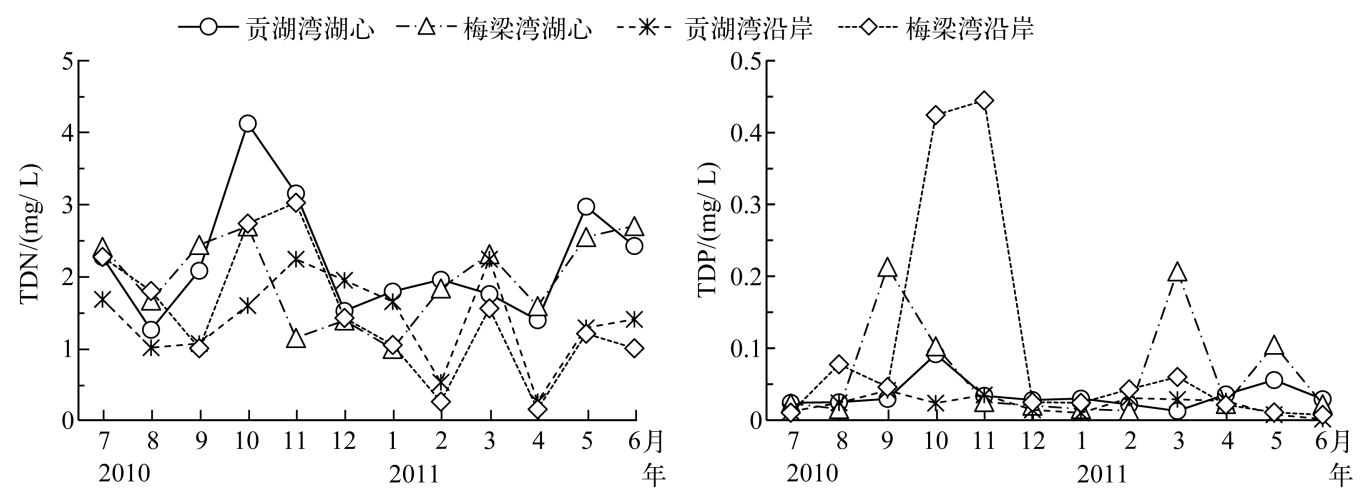

图 2 太湖贡湖湾和梅梁湾不同区域水体 TDN 和 TDP 的平均浓度

Fig. 2 Average concentrations of TDN and TDP in different areas in Gonghu Bay and Meiliang Bay of Lake Taihu 


\section{2 微囊藻群落的季节演替}

从贡湖湾和梅梁湾的微囊藻平均细胞丰度及各微囊藻种类的比例构成 (图 3) 可以看出, 7-11 月间, 微 囊藻平均细胞丰度较高, 种类构成较丰富, 各种微囊藻间存在明显的演替过程, 表现为 7 月份以鱼害微囊藻 为主, 8-9 月惠氏微囊藻占优势, 期间铜绿微囊藻所占比例不断增加并于 $10-11$ 月占优势; 12 月以后铜绿 微囊藻及惠氏微囊藻迅速减少, 鱼害微囊藻恢复优势地位; 而次年 1-4 月水体中微囊藻较少, 仅存在一些 粒径较小且难以区分形态的其它微囊藻, 5-6 月鱼害微囊藻出现并逐渐增加. 为探讨各微囊藻群落的空间 分布差异性, 将 2 个湖湾按湖心及沿岸区域进行划分, 统计同一区域中各微囊藻群落的变化过程 (图 4). 在 4 个不同区域中都存在明显的微囊藻群落的演替过程, 且变化过程与 2 个湖湾整体的统计结果类似. 尽管 4 个不同区域内微囊藻群落的分布存在一些差异, 但是较为随机, 并无明显规律.
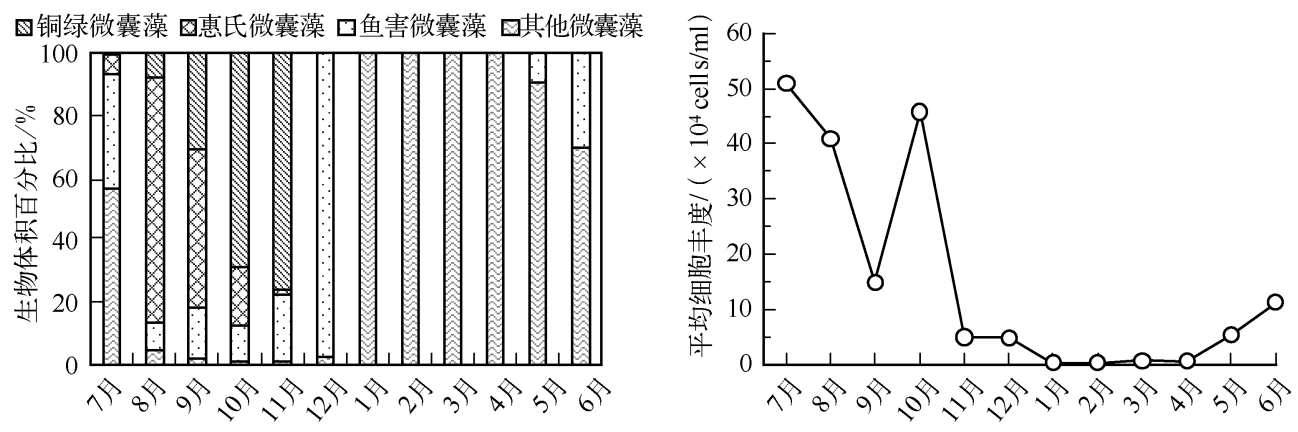

图 3 太湖贡湖湾和梅梁湾微囊藻群落的季节演替及平均细胞丰度的变化

Fig. 3 Seasonal succession and average cell abundance of Microcystis colonies in Gonghu Bay and Meiliang Bay of Lake Taihu
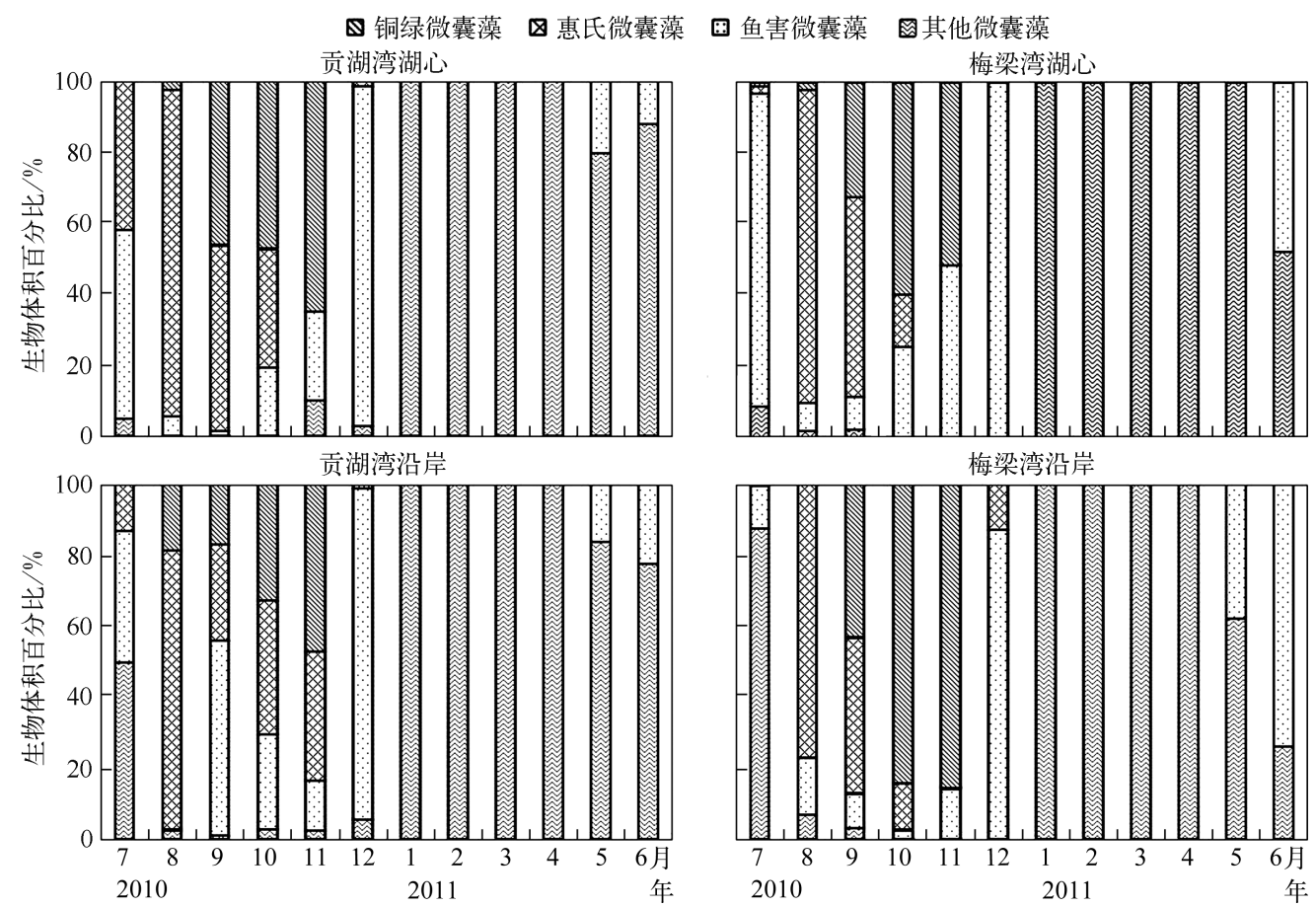

图 4 太湖贡湖湾和梅梁湾不同区域微囊藻群落的季节演替

Fig. 4 Seasonal succession of Microcystis colonies in different areas in Gonghu Bay and Meiliang Bay of Lake Taihu 


\section{3 环境因子与不同种微囊藻丰度间的关系}

对不同种微囊藻细胞丰度与各环境因子进 行 CCA 分析, 结果见表 $2 . \operatorname{TDN}(P=0.017)$ 、TDP 浓度 $(P<0.001)$ 与铜绿微囊藻细胞丰度呈显著 正相关, 而与惠氏微囊藻、鱼害微囊藻及其他微 囊藻细胞丰度并没有显著相关性 (图 5). 惠氏微 囊藻多出现在 $\mathrm{pH}$ 值较高的情况下, 而鱼害微囊 藻及其他微囊藻则正好相反. 水温、TDN:TDP与 铜绿微囊藻细胞丰度间的相关性并不明显. 风速 与风向对微囊藻不同种间分布的影响较为显著.

蒙特卡罗检验结果显示, 显著影响微囊藻不 同种间分布的主要环境因子有 TDN :TDP $(P=$ $0.002<0.01, F=24.60) 、$ TDP 浓度 $(P=0.002<$ $0.01, F=18.72)$ 、水温 $(P=0.002<0.01, F=$ $11.74) 、 \mathrm{pH}$ 值 $(P=0.002<0.01, F=8.99) 、 \mathrm{TDN}$ 浓度 $(P=0.032<0.05, F=3.11)$ 、风速 $(P=$ $0.044<0.05, F=3.05)$ 、风向 $(P=0.046<0.05$, $F=2.62)$. 其中 TDN:TDP、TDP 浓度和水温对微 囊藻种间分布的解释率高达 $83 \%$.

\section{4 微囊藻细胞丰度及群落的空间分布}

7-11 月太湖两个湖湾微囊藻的细胞丰度较 大,种类构成更为丰富 (图 3), 因此以该时段内 的微囊藻群落构成为研究对象, 分析各区域微囊 藻群落分布 (图 4) 产生差异的原因. 图 6 为 $7-$ 11 月两个湖湾中各样点不同种类微囊澡细胞丰 度的变化情况, 将各样点沿着风向进行排列可以 看出, 各样点的细胞丰度大小受风的影响十分明
表 2 CCA 分析前两轴的统计特征

Tab. 2 Statistics characteristics of the first two axes of CCA

\begin{tabular}{lcc}
\hline 统计指标 & 轴 1 & 轴 2 \\
\hline 特征值 & 0.330 & 0.217 \\
生物环境因子相关性 & 0.763 & 0.649 \\
生物多样性累计值 & 23.6 & 39.0 \\
生物环境因子相关性累计值 & 53.0 & 87.8 \\
\hline
\end{tabular}

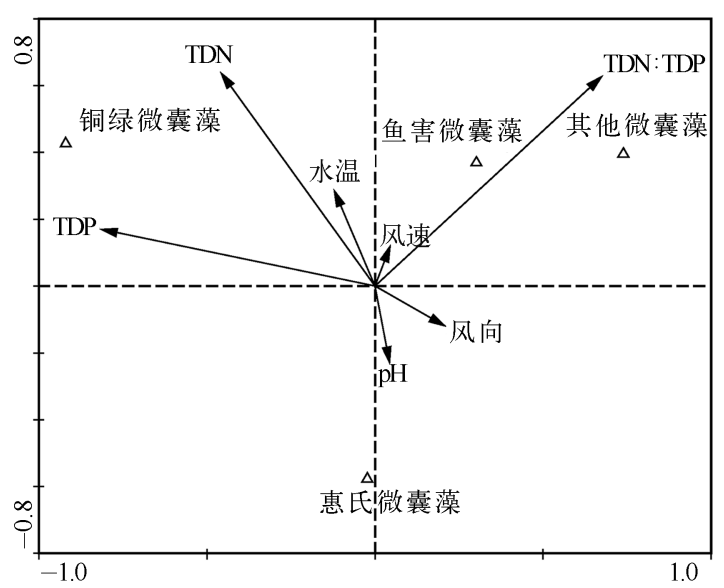

图 5 环境因子与不同种类微囊藻细胞 丰度关系的 CCA 结果

Fig. 5 CCA analysis between environmental factors and cell abundance of different Microcystis colonies

显, 位于下风向的各样点细胞丰度明显高于位于上风向的各样点. 且经过单项方差分析发现,7 月份梅梁湾 水体中铜绿微囊藻、惠氏微囊藻及鱼害微囊藻受到风向的影响极显著 $(P<0.01), 10$ 月份贡湖湾水体中的 鱼害微囊藻与风向之间呈显著相关 $(P<0.05)$, 而 11 月份贡湖湾及梅梁湾水体中分别为惠氏微囊藻 $(P<$ $0.05)$ 及铜绿微囊藻 $(P<0.01)$ 受风向影响显著.

\section{5 各微囊藻群体的粒径变化}

从图 6 可以看出,铜绿微囊藻和惠氏微囊藻较鱼害微囊藻和其它微囊藻更易受到风的影响而发生迁 移, 对四者的平均粒径进行比较 (图 7) 可以看出, 太湖两个湖湾中铜绿微囊藻、惠氏微囊藻、鱼害微囊藻及其 它微囊藻粒径大小规律一致: 铜绿微囊藻群体的平均粒径最大, 接近 $1000 \mu \mathrm{m}$; 惠氏微囊藻的粒径次之, 但平 均粒径基本在 $500 \mu \mathrm{m}$ 以上; 鱼害微囊藻粒径较小,但在 7 月份其粒径与铜绿微囊藻及惠氏微囊藻的相近; 而 其它微囊藻的平均粒径最小,基本在 $100 \sim 300 \mu \mathrm{m}$ 之间.

\section{3 讨论}

2010 年 7 月至 2011 年 6 月间,太湖贡湖湾和梅梁湾内存在明显的微囊藻群落演替现象. 在 7-11 月 间, 太湖梅梁湾及贡湖湾微囊藻种类构成丰富, 以鱼害微囊藻、惠氏微囊藻及铜绿微囊藻为主, 且整体上都 表现为鱼害微囊藻、惠氏微囊藻及铜绿微囊藻顺次成为优势种的演替过程 (图 3、4); 12 月以后种类构成单 一, 以鱼害微囊藻和其它微囊藻为主. 这与 Park 等 ${ }^{[4]}$ 对日本诹访湖、Yamamoto 等 ${ }^{[6]}$ 对 Hirosawa-no-ike Pond 和贾晓会等 ${ }^{[7]}$ 对巢湖调查得到的规律相近. 

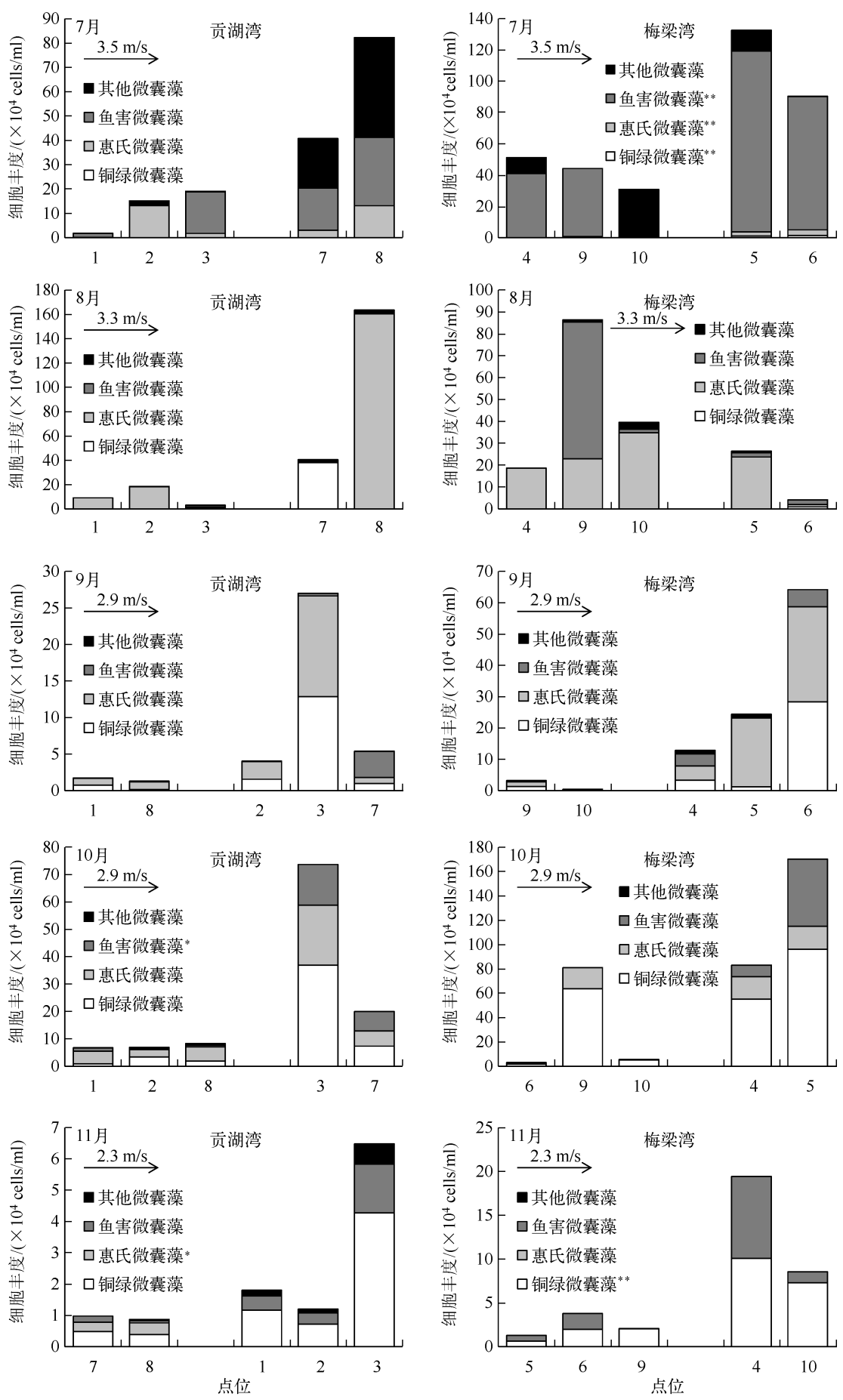

图 6 太湖贡湖湾和梅梁湾微囊藻群落的空间分布及其与风的关系

$$
(* \text { 表示 } P<0.05, * * \text { 表示 } P<0.01)
$$

Fig. 6 Spatial distribution of Microcystis colonies and the relationship with wind in Gonghu Bay and Meiliang Bay of Lake Taihu 


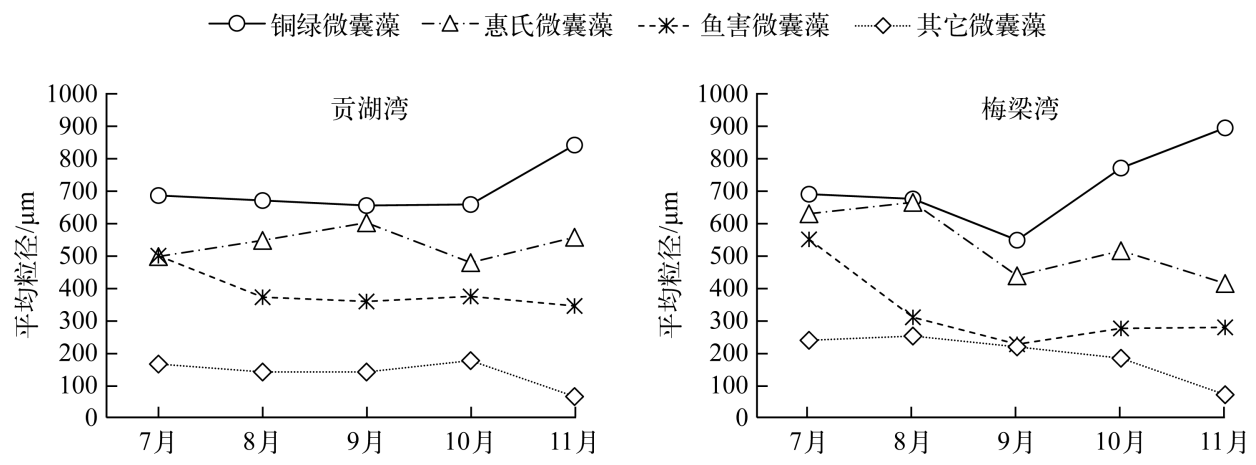

图 7 太湖贡湖湾和梅梁湾不同微囊藻群体的平均粒径

Fig. 7 The mean size of colonies of different Microcystis species in Gonghu Bay and Meiliang Bay of Lake Taihu

氮、磷浓度是影响浮游植物生长的重要环境因子 ${ }^{[20]}$. 本研究通过 CCA 分析发现,铜绿微囊藻出现在 TDN 和 TDP 浓度较高的环境中, 而惠氏微囊藻与两者的相关性并不显著. TDN:TDP 与铜绿微囊藻和惠氏微 囊藻丰度间的相关性并不明显, 与鱼害微囊藻 $(P<0.05)$ 及其它微囊藻 $(P=0.01)$ 丰度呈正相关, 这可能是 由不同微囊藻对营养盐的需求不同所导致的. 不同种微囊藻与 TDN 浓度、TDP 浓度、TDN:TDP 等的相关性 存在差别, 也可能导致微囊藻的季节演替. 但是不同湖泊中上述营养盐浓度相差较大, 如中国的巢湖和太湖 营养盐浓度较高, 而日本的诹访湖等湖泊营养盐浓度要低很多. 然而, 湖泊中微囊藻种的演替规律却十分相 似. Honma 等 ${ }^{[21]}$ 对日本琵琶湖的微囊藻群落组成进行研究, 发现 N、P 浓度对微囊藻组成有所影响, 但对演 替过程的影响却不明显. 可见, 营养盐的差异不能解释多数湖泊中不同种微囊藻的季节演替现象. 此外, 尽 管 CCA 结果显示 $\mathrm{pH}$ 值与不同微囊藻间相关性差异较大, 但由于湖泊中 $\mathrm{pH}$ 值的变化范围很小, 基本上可以 排除其作为不同种微囊藻间演替的驱动因子的可能.

Imai 等 ${ }^{[12]}$ 认为温度是微囊藻属各种类发生演替的驱动因子, 铜绿微囊藻适于在较高水温中生长, 而惠 氏微囊藻则在较低水温中生长得更好. Ohkubo 等 ${ }^{[22]}$ 对霞浦湖的调查也发现, 铜绿微囊藻细胞丰度与水温之 间存在明显的相关性. 本研究通过 CCA 分析发现, 水温与铜绿微囊藻细胞丰度呈正相关 $(P>0.05)$, 而与惠 氏微囊藻 $(P=0.071)$ 及鱼害微囊藻 $(P=0.031)$ 细胞丰度呈负相关, 这与他们的结论一致. 这可能是因为相 比于惠氏微囊藻, 铜绿微囊藻在高温环境中更易增殖生长. 而野外观察发现, 在温度较低的冬季及初春水体 中以鱼害微囊藻和其它微囊藻为主. 因此,温度可能是驱动太湖微囊藻季节演替的重要因素.

不同区域微囊藻群体的种类组成存在差异. Otten 等 ${ }^{[11]}$ 发现太湖湖心区域以惠氏微囊藻和水华微囊藻 为主, 而岸边以铜绿微囊藻为主. $\mathrm{Wu}$ 等 ${ }^{[23]}$ 分析了太湖微囊藻的水平迁移, 指出太湖微囊藻的水平迁移主要 是由风引起的表层迁移. 本研究结果表明, 受风的影响微囊藻存在空间上的迁移,位于下风向样点的细胞丰 度明显高于位于上风向的样点. 且通过单项方差分析发现, 铜绿微囊藻和惠氏微囊藻更易受到风的影响而 发生迁移. 铜绿微囊藻、惠氏微囊藻、鱼害微囊藻以及其它微囊藻的群体粒径大小存在明显的规律性, 铜绿 微囊藻和惠氏微囊藻的群体粒径较大, 而鱼害微囊藻及其它微囊藻的群体粒径较小. 而 Zhu 等 $^{[24]}$ 指出大粒 径的惠氏微囊藻和铜绿微囊藻群体更容易漂浮在表层. 由此可见, 本研究中下风向样点惠氏微囊藻和铜绿 微囊藻生物量较高是因为它们易于漂浮在表层而通过表层迁移聚集于下风向处.

\section{4 参考文献}

[ 1 ] Prescott GW. Objectionable algae with reference to the killing of fish and other animals. Hydrobiologia, 1948, 1(1): 113.

[ 2 ] Paerl HW, Fulton RS, Moisander PH et al. Harmful freshwater algal blooms, with an emphasis on cyanobacteria. The Scientific World Journal, 2001, 1: 76-113.

[ 3 ] Sivonen K, Jones GG. Toxic cyanobacteria in water: a guide to their public health consequence, monitoring and manage- 
ment. London: E and FN Spon, 1999: 41-111.

[ 4 ] Park HD, Watanabe MF, Harada KI et al. Seasonal variations of Microcystis species and toxic heptapeptide microcystins in Lake Suwa. Environmental Toxicology and Water Quality, 1993, 8(4) : 425-435.

[ 5 ] Ozawa K, Fujioka H, Muranaka M et al. Spatial distribution and temporal variation of Microcystis species composition and microcystin concentration in Lake Biwa. Environmental Toxicology, 2005, 20(3) : 270-276.

[ 6 ] Yamamoto Y, Nakahara H. Seasonal variations in the morphology of bloom-forming cyanobacteria in a eutrophic pond. Limnology, 2009, 10(3) : 185-193.

[7] 贾晓会, 施定基, 史绵红等. 巢湖蓝藻水华形成原因探索及 “优势种光合假说”. 生态学报, 2011,31 (11): 2968-2977.

[ 8 ] 陈宇炜, 高锡云. 太湖梅梁湾浮游植物动态及其初级生产力周年变化的研究. 见: 蔡启铭编. 太湖环境生态研究. 北 京:气象出版社,1998: 98-108.

[9] 谭 啸,孔繁翔,曾庆飞等. 太湖中微囊藻群落的季节变化分析. 生态与农村环境学报,2009,25(1): 47-52.

[10 ] Li M, Zhu W, Gao L et al. Seasonal variations of morphospecies composition and colony size of Microcystis in a shallow hypertrophic lake(Lake Taihu, China). Fresenius Environmental Bulletin, 2013, 22 (12) : 3474-3483.

[11] Otten TG, Paerl HW. Phylogenetic inference of colony isolates comprising seasonal Microcystis blooms in Lake Taihu, China. Microbial Ecology, 2011, 62: 907-918.

[12] Imai H, Chang KH, Kusaba M et al. Temperature-dependent dominance of Microcystis (Cyanophyceae) species: M. aeruginosa and M. wesenbergii. Journal of Plankton Research, 2009, 31(2) : 171-178.

[13] Amemiya Y, Okino T, Nakayama O. Factors possibly affecting dominance of Microcystis species. Janpanese Journal of Limnology, 1990, 51(1) : 9-13.

[14] Xing W, Huang WM, Li DH et al. Effects of iron on growth, pigment content, photosystem II efficiency, and siderophores production of Microcystis aeruginosa and Microcystis wesenbergii. Current microbiology, 2007, 55(2) : 94-98.

[15] Davis TW, Berry DL, Boyer GL et al. The effects of temperature and nutrients on the growth and dynamics of toxic and non-toxic strains of Microcystis during cyanobacteria blooms. Harmful Algae, 2009, 8(5) : 715-725.

[16] 金相灿, 屠清瑛. 湖泊富营养化调查规范. 北京:中国环境科学出版社,1990: 160-185.

[17] 虞功亮, 宋立荣, 李仁辉. 中国淡水微囊藻属常见种类的分类学讨论一一滇池为例. 植物分类学报, 2007,45(5): 727-741.

[18 ] Watanabe MM. Isolation, cultivation and classification of bloom-forming Microcystis in Japan. In: Watanabe MF, Harada K, Carmichael WW et al eds. Toxic Microcystis. Boca Raton, FL: CRC Press, 1996: 13-34.

[19] Joung S, Kim C, Ahn C et al. Simple method for a cell count of the colonial cyanobacterium, Microcystis sp. . The Journal of Microbiology, 2006, 44(5) : 562-565.

[20 ] Elser JJ, Marzolf ER, Goldman CR. Phosphorus and nitrogen limitation of phytoplankton growth in the freshwaters of north America: a review and critique of experimental enrichments. Canadian Journal of Fisheries and Aquatic Sciences, 1990, $47(7): 1468-1477$.

[21] Honma T, Park HD. Influences of nitrate and phosphate concentrations on Microcystis species composition and microcystin concentration in Lake Suwa. Journal of Japan Society on Water Environment, 2005, 28 (6) : 373-378 (in Japanese).

[22] Ohkubo N, Yagi O, Okada M. Studies on the succession of blue-green algae, Microcystis, Anabaena, Oscillatoria and Phormidium in Lake Kasumigaura. Environmental Technology, 1993, 14(5) : 433-442.

[23] Wu XD, Kong FX, Chen YW et al. Horizontal distribution and transport processes of bloom-forming Microcystis in a large shallow lake( Taihu, China). Limnologica, 2010, 40(1): 8-15.

[24] Zhu W, Li M, Luo YG et al. Vertical distribution of Microcystis colony size in Lake Taihu: Its role in algal blooms. Journal of Great Lakes Research, 2014, 40 :949-955. 